\title{
Plateros para el Inca: la traducción de documentos en lengua general al castellano en la Audiencia de Lima a fines del siglo XVII*
}

\section{Silversmiths for the Inca: The Translation of Documents from the General Language to Spanish in the Late Seventeenth-Century Lima Audiencia}

JOSÉ CARLOS DE LA PUENTE LUNA

Texas State University

jd65@txstate.edu

\section{RESUMEN}

Un documento de 1693 esclarece la labor de traducción de testimonios escritos en lengua general al castellano por parte de los intérpretes de los naturales de la Audiencia de Lima. El caso demuestra el uso oficial de la escritura en quechua como vehiculo de la justicia ordinaria y refuerza la idea de que la labor de interpretación en un contexto plurilingüe como el del circuito de la Audiencia fue posible gracias al uso de una o más variantes estándar de quechua, por parte de traductores y litigantes, hasta bien entrado el siglo XVII.

Palabras clave: quechua, lengua general, intérpretes, cultural legal, Yauyos

\footnotetext{
${ }^{*}$ Este trabajo se redactó durante una estancia de investigación en el Instituto de Estudios Históricos de la Universidad de Texas en Austin. Mi agradecimiento al Instituto y a los departamentos de Historia de dicha universidad y de la Universidad del Estado de Texas por financiar mi estadía. Mi deuda de gratitud también con Teresa Vergara y a Jimmy Martínez Céspedes por alertarme de la existencia de los dos manuscritos que se citan en las notas 20 y 25, respectivamente. Jimmy tuvo además la gentileza de compartir una copia conmigo.
}

HISTORICA XLIII.2 (2019): 149-168 / ISSN 0252-8894 


\section{ABSTRACT}

A 1693 document sheds light on the translation into Castilian of witness testimonies uttered in the lengua general and recorded in writing a century earlier, as part of the activities of the interpreters-general in Lima's appellate court (audiencia). The case demonstrates the official admission of written Quechua in judicial procedures as late as the closing decades of the seventeenth century. It reinforces the idea that the use of one or more standard varieties of Quechua by litigants and interpreters made the interpretive work of these translators in plurilingual contexts such as the court's judicial district possible.

Keywords: Quechua, lengua general, interpreters, indigenous legal culture, Yauyos

l acceso de las poblaciones nativas a los foros eclesiásticos y reales
de justicia fue una práctica consustancial al establecimiento y la continuidad del orden colonial en el Nuevo Mundo. La interacción entre hablantes de una multiplicidad de lenguas y la subordinación de estas a un puñado de linguas francas, incluido el castellano, fueron los pilares de una praxis muy extendida que confirió a la tarea de los intérpretes un carácter indispensable. En el Perú colonial, así como en otras partes, incontables personajes actuaron como tales, con título o sin él, en un sinfín de interacciones públicas y privadas, rutinarias y esporádicas, así como en toda clase de procesos administrativos y judiciales. Los intérpretes generales de los naturales de la Audiencia de Lima representan uno de los casos más visibles de este tipo de función mediadora. ${ }^{1}$

En contraste con el panorama historiográfico de hace solo unos años, hoy conocemos relativamente bien la historia de la plaza de intérprete

${ }^{1}$ La aparición de dos volúmenes dedicados a intérpretes y mediación lingüística en 2019 grafica la vigencia de esta temática (Cunill y Glave 2019; Yannakakis y Schrader-Kniffki 2019). Para un balance reciente, Cunill 2019. Esta historiografía se enlaza con una literatura más amplia sobre agentes mediadores y la relación entre poblaciones indígenas y la palabra escrita, sobre todo en sus variantes misional y judicial (Tavárez 2019). 
general, puesto de confianza del virrey. ${ }^{2}$ La participación de los intérpretes generales, de la mano de testigos y declarantes, virreyes, oidores, defensores, visitadores y corregidores, en la elaboración de numerosos instrumentos notariales y judiciales, está cada vez mejor atestiguada. Las trayectorias de quienes ocuparon el cargo entre los siglos XVI y XVIII, sus aspiraciones y mecanismos de ascenso y consolidación social, han dejado de ser territorio desconocido. Su rol articulador de diversas instancias de justicia — locales, regionales y transatlánticas - ha sido puesto de manifiesto. Junto con el honor y prestigio que el cargo confirió a los favorecidos, son todos temas propios de la discusión historiográfica actual, gracias a una década sostenida de investigaciones. ${ }^{3}$

Más allá de la firma y la rúbrica acostumbradas, sin embargo, la labor estrictamente lingüística de los intérpretes de los naturales del distrito limeño, así como su relación con la lectoescritura en quechua y castellano, siguen siendo temas difíciles de explorar. ${ }^{4}$ Por regla general, este tipo de interpretación oral eliminaba sus propias huellas. En otras palabras, los documentos recogen una tarea ya concluida: la interpretación definitiva y en castellano, dictada al escribano o a alguno de sus amanuenses, de uno o más testimonios emitidos en otras lenguas casi simultáneamente, de los cuales no queda más registro que la traducción. ${ }^{5}$ Muy rara vez, las fuentes contienen evidencias sobre aspectos metalingüísticos, es decir, reflexiones sobre las expresiones originales, las alternativas de traducción y, en general, las distintas estrategias lingüísticas de los intérpretes. ${ }^{6}$ Por otra parte, la amplia difusión del castellano entre las poblaciones nativas

2 Fossa 2006; Novoa 2016: 45; Puente Luna y Solier Ochoa 2006; Ramos 2011.

3 Huamanchumo de la Cuba 2015 y 2016; Jurado 2010; Puente Luna 2014; Ramos 2011: 25-29. El trabajo reciente de Luis Miguel Glave (2019) reúne abundante información al respecto, en buena medida desconocida.

${ }^{4}$ Una excepción notable es la de Felipe Guaman Poma de Ayala, intérprete comisionado por la Audiencia en 1594 y autor de Nueva corónica y buen gobierno (1616). La información conocida sobre esta faceta de su vida y su relación con la Nueva corónica queda reunida en Puente Luna y Solier Ochoa 2006.

5 Andrade Ciudad y Bell 2016: 449 y nota 7; Cunill 2019: 5.

6 Algunas excepciones se discuten en Abercrombie 2002; Glave 2019: 129-147; Murra 1998: 57-58. 
que residían en Lima, así como la multiplicidad de lenguas y dialectos que, en teoría, el intérprete general del distrito de la Audiencia hubiese tenido que dominar, además del castellano, le confieren un halo de misterio a su trabajo diario de interpretación. Muy probablemente, algunos intérpretes generales fueron competentes en varias lenguas y dialectos (como sucedía en México), pero necesitamos más documentación al respecto. ${ }^{7}$

Debido a estos vacíos y a los retos de la interpretación en un distrito multilingüe como el de la Audiencia, se ha sugerido la posibilidad de que la función de intermediación legal, política y social de los intérpretes generales, su posición en tanto guardianes de la instancia superior de justicia, dominio de virreyes, oidores y abogados de naturales, opacase los aspectos puramente formales de la plaza. ${ }^{8}$ En realidad, ambas cosas no se excluyen mutuamente, como veremos en esta nota. El testimonio que se publica no es suficiente para alterar nuestra visión predominante de los intérpretes de la Audiencia, incluida su participación en una serie de prácticas de justicia y de regímenes de verdad que privilegiaban el castellano por sobre otras lenguas, especialmente en su versión escrita, letrada y notarial. Como otros han señalado, los intérpretes se insertaban en una constelación de relaciones sociales jerárquicas, construidas en torno a la hegemonía de la escritura alfabética en castellano, la famosa ciudad letrada. ${ }^{9}$ Sin embargo, el documento que publicamos introduce un matiz importante, pues muestra que, en algunos casos, documentos escritos en lenguas nativas fueron aceptados como medios probatorios por la Audiencia y traducidos internamente. Como parte de sus labores en la corte limeña de apelaciones, entonces, los intérpretes podían ser llamados a traducir documentos originalmente escritos en quechua, en

7 Para una discusión detallada de los intérpretes de la Audiencia de México, en donde se interpretaba otomí, tarasco, mixteco y náhuatl, véase Cunill 2018. Sobre el papel de mediación del intérprete general de Yucatán —el Ah Tzol Than o «cambiador de palabras»— véanse Cunill 2013; Lentz 2009 y 2019. Para la situación en Oaxaca, véanse Yannakakis 2014; Yannakakis y Schrader-Kniffki 2016.

8 Puente Luna 2014; Ramos 2014: 29.

9 Dueñas 2015; Rama 1996; Ramos y Yannakakis 2014; Rappaport y Cummins 2012. 
una variante aparentemente estándar identificada como «lengua general» a fines del siglo XVII.

El caso que presentamos refleja un escenario distinto de aquel en el que se enmarcan los actos de interpretación a los que estamos acostumbrados para el caso peruano pero que no era desconocido en Nueva España. ${ }^{10}$ Sus detalles refuerzan la idea de que la labor de traducción de los intérpretes en un contexto plurilingüe como el del circuito de la Audiencia de Lima fue posible gracias al uso de una o más variantes estándar de quechua, por parte de traductores y litigantes, hasta bien entrado el siglo XVII. ${ }^{11}$ Sin más ejemplos análogos que exponer por ahora, referidos al uso oficial de la escritura en quechua como vehículo de la justicia, es imposible pronunciarse sobre el carácter excepcional o corriente de la dinámica capturada en el documento. Podemos sugerir, sin embargo, que se trata de una instancia relativamente excepcional pero no del todo ajena a la cultura legal andina, un escenario en el cual la traducción de testimonios originales en lengua general, de por sí sumamente escasos, se volvía imprescindible para que las partes alcanzaran justicia. ${ }^{12}$

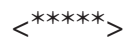

${ }^{10}$ En Yucatán, los intérpretes generales de los siglos XVII y XVIII traducían quejas, peticiones y títulos de tierras escritos en maya regularmente. Además, preparaban bandos y otras órdenes oficiales en maya para su proclamación. Algunos tomaban directamente declaraciones en maya. Mark Lentz trae a colación el caso del intérprete Francisco Ruz, quien al parecer se especializaba en traducir textos escritos antes que en interpretar declaraciones orales (2009: 147-148). Cunill señala, para el caso novohispano en el siglo XVI, que los intérpretes generales de la Audiencia consultaban los documentos pictográficos y escuchaban su recitación en voz alta por parte de los litigantes, para preparar su versión en castellano (2018: 15).

${ }^{11}$ Andrade Ciudad y Bell 2016: 455; Estenssoro 2015: 25; Itier 2011: 72-73; Puente Luna 2014: 9. La situación análoga del náhuatl y el pipil en Oaxaca y Guatemala coloniales se discute en Matthew y Romero 2012; Yannakakis 2008.

${ }^{12}$ Sobre la producción de documentos en quechua fuera del ámbito pastoral, véanse Argouse 2014; Durston y Urioste 2013; Durston 2003 y 2008. Algunos de estos escritos fueron preparados ex profeso para los jueces eclesiásticos del Arzobispado. 
Los hechos se produjeron a fines de abril de 1693, cuando el procurador general de los naturales de la Audiencia solicitó a los magistrados del tribunal que el intérprete nombrado «redujese» las declaraciones de unos «indios antiguos» a la lengua de Castilla. El intérprete general al que se aludía era don Pablo Fernández Colquiruna, sobre quien ofreceremos algunas pistas después. El procurador representaba a los principales y común del pueblo de Santiago de Carania, en el corregimiento de Yauyos, quienes litigaban por unos pastos con su contraparte en el vecino pueblo de San Pedro de Piños. El carácter aditivo del expediente que se formó en la Audiencia (ahora en la Biblioteca Nacional del Perú), así como su foliación irregular y trunca, muestran que se elaboró a partir de instrumentos anteriores, generados ante magistrados locales (visitadores y corregidores), y que ya para entonces habían pasado a conformar los «títulos» de alguno de los comunes de Yauyos (posiblemente, Piños). ${ }^{13}$ Merced a los escritos de los procuradores, quienes se basaron en los antiguos expedientes que tenían a la vista, y que presumiblemente los litigantes trasladaron a Lima desde Yauyos, sabemos que, a fojas 40 de los autos originales había un instrumento «de mucho aprecio por su antigüedad» $\mathrm{y}$, a fojas 44, un plano del pueblo de Piñas, "con sus tierras y pastos adyacentes», ambos ahora perdidos. Igual de importante, a fojas 9, 11 y 12, se incluían instrumentos «en lengua general». En opinión del procurador, estos recaudos «influyen mucho en la justicia de mis partes» $\mathrm{y}$, para que los abogados pudiesen valerse de ellos, era preciso ingresar su contenido al registro oficial, así fuera en la versión del intérprete Pablo Fernández Colquiruna. En opinión del procurador, los recaudos, de más de un siglo de antigüedad, mostrarían cómo Carania había disfrutado de los parajes ahora en disputa desde el tiempo de Tupac Yupanqui.

${ }^{13}$ Una certificación de 21 de octubre de 1701 señala, por ejemplo, que la primera parte del expediente actual es un traslado de instrumentos originales que, junto con un mapa, fueron devueltos «a nuestro pueblo [Piños] para que se pongan en el archivo». («Expediente de la causa seguida por Melchor de Carbajal, procurador de naturales, en nombre del cacique principal y común del repartimiento de Atun Yauyos y el pueblo de Santiago de Carania, contra el pueblo de San Pedro de Pinos por la posesión de unas tierras. 1688. Biblioteca Nacional del Perú [en adelante BNP]. Mss. B889). 
La lengua general es parte de un debate incesante que escapa a los objetivos de esta introducción. Tanto su significado como sus múltiples referentes fueron cambiando entre los siglos XVI y XVII. Comúnmente identificada como «del Inga» o «del Cuzco», podía referirse a la familia lingüística del quechua, a la lengua común de los valles y las quebradas de clima templado que sirvió de vehículo a la expansión del Tahuantinsuyo o a la variedad de quechua sureño propia de los incas. El sustrato o sustratos que sirvieron de base a la lengua general colonial, hija privilegiada de la ciudad, de la actividad misional y gubernativa y de la interacción asimétrica entre hablantes de castellano y de otras lenguas, así como la relación entre la versión hablada de la lengua general (con posibles variedades regionales) y la estándar escrita, siguen siendo materia de debate. ${ }^{14}$ Lo que importa para esta discusión es que, ya a comienzos del siglo XVII, se asumía que, aunque el virreinato peruano contenía diversas lenguas maternas (o particulares) y generales, la lengua general del Perú era el quechua, "por ser la lengua que hablaba el Inca», además de aquella que los intérpretes de la Audiencia debían dominar. ${ }^{15}$

$\mathrm{La}$ «lengua general» era una de las varias lenguas presentes en Yauyos — probablemente, no solo en su versión escrita— a fines del siglo XVI. ${ }^{16}$ Algo sabemos sobre el contexto de elaboración de estos instrumentos. Hace unos ańos, Gérald Taylor y Margot Beyersdorff estudiaron un corpus en quechua y castellano proveniente del valle de Jauja (pero referido a Yauyos), el cual, hasta este momento, se consideraba el documento judicial más antiguo de su tipo. Dos textos cortos, uno en castellano

${ }^{14}$ Durston 2007: 109-110, y 2014b; Estenssoro 2015; Itier 2011 y 2015; King y Hornberger 2006; Taylor 2000b.

${ }^{15}$ Estenssoro 2015 15. Glave reseńa el caso de Tomás López, quien en 1625 se decía «intérprete de la lengua general de aquella tierra y materna y quichua en tres o cuatro lenguas» (Glave 2019: 155). Sobre las habilidades lingüísticas de Juan Vélez, natural del valle de Jauja e intérprete de la Audiencia en 1615, sus contemporáneos opinaban que, "quando [los caciques de Jauja] oyan hablar al dicho Joan Velez en la lengua [general,] les parescia que era desendiente de yngas por que hablaba como ellos» (Puente Luna 2014: 150 y nota 125). Sobre las diferencias entre lenguas generales, maternas y particulares, véase Estenssoro 2015.

16 Taylor 2000b. 
y otro en lengua general, fueron incluidos en un mapa o "papelón» que representaba el reconocimiento, y en algunos casos el traslado, de las rayas y los mojones que señalaban los pastos del pueblo de Santo Domingo de Cochalaraos, uno de los más importantes de la provincia de los Yauyos. ${ }^{17}$ Dado que estos pastos colindaban con los pastos de Chupaca, Chongos y Sicaya, siete «hombres viejos y ancianos» de estos tres pueblos de la vecina provincia de Jauja fueron convocados como testigos del recorrido y la delimitación de dichos territorios en agosto de 1597. En presencia del cacique del repartimiento de Laraos y Aymaraes, cuya jurisdicción incluía el pueblo de Cochalaraos, el escribano dejó constancia de los actuados en castellano y en quechua, señalando que los pastos habían sido divididos por merced de Túpac Inca Yupanqui. Otro mapa, preparado dos años antes, había registrado los mismos pastos y linderos, atribuyendo la repartición al mismo rey. Fuentes contemporáneas corroboran esta versión. ${ }^{18}$

Los testimonios que el intérprete general de la Audiencia traduciría en 1693 reflejan esta misma coyuntura y abordan la misma temática (la competencia por los pastos), pero anteceden a los conocidos de 1595 y 1597 en tres y cinco años, respectivamente. La fecha más temprana de los documentos que el intérprete tradujo sugiere que los litigios por los pastos y corrales de las alturas de Yauyos y Jauja habían comenzado ya en 1592 y que se resolverían, al menos momentáneamente, durante la Primera Visita y Composición de Tierras (1594-1597), con el reconocimiento de los pueblos de Jauja de los derechos de sus vecinos en Yauyos, asentados al oeste del proverbial valle de los huancas. Taylor ha argumentado convincentemente que el texto quechua de 1597 que acompaña

\section{${ }^{17}$ Sobre esta antigua práctica, véase Radcliffe 1990.}

18 Beyersdorff 2007; Taylor 2000a. Ambos autores identificaron Yauyos como el lugar de procedencia de los documentos, quizás guiados por la inclusión de estos en los títulos de la moderna comunidad de Laraos. Claramente, sin embargo, dichos documentos fueron preparados por el escribano de cabildo de San Juan Bautista de Chupaca, un pueblo en el repartimiento de Ananguanca, en la parte sur del valle de Jauja. Sobre la producción de escritura en castellano en los cabildos de naturales de la zona, véase Puente Luna 2016. Sobre incas y pastos, consultar la relación de la provincia de Yauyos compuesta por Diego Dávila Briceño (Jiménez de la Espada 1881-1897, I: 78). 
al conocido mapa de Cochalaraos es un "calco» del original castellano, sin el cual su sentido es imposible de reconstruir. ${ }^{19}$ En contraste, las dos declaraciones en lengua general de 1592, las mismas que solo han llegado a nosotros en castellano, demuestran que, al menos en el caso de esta constelación de documentos judiciales referidos a límites entre comunidades de Yauyos (y entre ellas y su contraparte en Jauja), el uso del quechua no se redujo a lo "simbólico», sino que fue parte de la elaboración del expediente judicial original, cuya extensión primigenia es ahora imposible de precisar. Dos testigos brindaron su versión de los hechos materia de disputa directamente en quechua, durante algún tipo de diligencia o averiguación, sin necesidad de intérprete. Los documentos bilingües de 1597 estudiados por Taylor y Beyersdorff, entre otros, demuestran que, en esta zona de la sierra de Lima, los escribanos de cabildo redactaban regularmente en castellano y en la variante de la lengua quechua conocida como «lengua general». Uno de ellos debió recoger las declaraciones en 1592. Aún a fines de la década de 1660, los padres dominicos a cargo de las doctrinas de Laraos (uno de los repartimientos de la provincia de Yauyos) predicaban regularmente en «la lengua general y quichua», mientras que los alcaldes de la doctrina de Atunyauyos a veces pregonaban en «lengua de indio». ${ }^{20}$

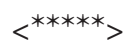

19 «El documento quechua en cuestión parece sobre todo haber tenido la función de símbolo. La torpeza de su construcción muestra una traducción del castellano hecha casi palabra por palabra» (Taylor 2000a: 101).

20 «Autos que se siguieron por el padre maestro de la orden, visitador que en virtud del real exorto embió el padre provincial contra los 7 curas de la provincia de los Yauyos» (Archivo de la Provincia Dominica de San Juan Bautista del Perú, Autos, Libro 13 [1667], fs. 648, 692). En Huarochirí (Lurin-Yauyos) se produjo uno de los documentos judiciales más antiguos en lengua general (Taylor 2000b). La relación entre la famosa retracción de 1608 y el manuscrito quechua de Huarochirí, escrito también en lengua general, se explora en Durston 2014a. La relación de larga data de estas poblaciones con la escritura alfabética se discute magistralmente en Salomon y Niño-Murcia 2011. 
La figura del capitán Pablo Fernández Colquiruna, a cargo de la traducción de 1693, domina la plaza de intérprete general de la Audiencia de Lima durante la segunda mitad del siglo XVII. Aunque poco sabemos de su vida antes de este momento, había ocupado la codiciada plaza limeńa por más de treinta ańos. Natural de Chota, en Cajamarca (un detalle interesante para pensar su labor lingüística), casó en La Barranca, cerca de Lima, en $1674 .{ }^{21}$ Un miembro de su linaje fue gobernador de las siete guarangas de Cajamarca en la década de $1560 .{ }^{22}$ Como otros notables de la sociedad indo-limeña de su tiempo, incluidos varios de los intérpretes de la Audiencia que lo precedieron, Fernández Colquiruna pertenecía a la oficialía de una de las milicias de naturales de la ciudad. ${ }^{23} \mathrm{Al}$ igual que en esos casos, el patronímico castellano generalmente precedía al apellido quechua (a menos que la ocasión aconsejara enfatizar la ascendencia india). ${ }^{24}$ Fernández Colquiruna combinaba, como sus predecesores, la labor de interpretación con la de procurador de causas. En 1661, enjuició a la cofradía de indios de Nuestra Señora de la Candelaria por el pago de 150 pesos, una cantidad acorde con el censo de 1,100 pesos que ayudó a cobrar en favor de la hermandad. El intérprete ganó el juicio. ${ }^{25}$

21 «Don Pablo Fernandes con Dońa Maria de Palma. Velados». Archivo del Obispado de Huacho, Parroquia de San Ildefonso de La Barranca, Libro de Matrimonios y Defunciones 1 (1646-1736) [1674], f. 76v-77. Estuvo casado antes con María Rufina, india natural de Santo Domingo de Sisicaya (Huarochirí), viuda de Baltasar de Santiago. Don Pablo era hijo de Felipe Bautista y María Talcay (o Gualcay). «Don Pablo Fernández con María Rufina». Archivo Arzobispal de Lima [en adelante AAL], Parroquia del Sagrario de Lima, Libro de Matrimonios de Indios (1620-1657) [1654], f. 367.

22 Rostworowski 1977: 275.

${ }^{23}$ Glave 2009; Puente Luna 2014; Puente Luna 2018. Sobre sus funciones en el cargo, véanse los documentos que tramitó ante la Caja General de Censos para cobrar su salario anual de 250 pesos ensayados (BNP. Mss. B285 y B366).

${ }^{24} \mathrm{Su}$ hijo, Felipe Isidoro Apo Colquiruna, natural de Lima, sería pieza importante en las redes vinculadas a Vicente Mora Chimo y la ejecución de la llamada «cédula de los honores» de 1697 (Glave 2011: 15-16; Mathis 2017: 264-266). Casó en 1703 con Doña Beatriz de Ovalle, identificada como «mestiza» y natural de Ica, hija legítima de Pedro Aybar y de Augusta Xallo (Libro de Matrimonio de Indios (1700-1782) [1703], AAL, f. 20v.).

${ }^{25}$ AAL, Cofradías VI-A:4 [1661-1662]. 
Más de treinta años después, en 1693, Fernández Colquiruna se daría cita en el oficio del escribano de cámara Francisco de Quesada para examinar una serie de papeles en «lengua general de los naturales». Tras examinar los documentos, el intérprete dictó su versión in situ. Dos fueron las declaraciones que vertió al castellano: la de Alonso Atoc Ñaupa y la de don Alonso, ambos, al parecer, principales y, por tanto, candidatos idóneos para conocer la lengua general en 1592. Fernández Colquiruna parece haberse desviado del contenido literal de los documentos en momentos clave, quizás a pedido de los abogados de las partes, para glosar una serie de términos relevantes para el caso. Sobre los topónimos que identificaban los mojones y canchas (corrales) de Carania, por ejemplo, el intérprete interpuso lo siguiente: «Guascacocha Cancha este nombre se ynterpreta y quiere desir Corral; Quinoa Cancha este nombre se ynterpreta tierras de árboles que llaman quingua; Canchanacancha mojon: este nombre se interpreta y quiere desir arroyuelo que corre el agua». ${ }^{26}$

Es poco probable que la explicación del significado de cada corral estuviese en los instrumentos que Fernández Colquiruna tuvo ante sí. El testigo (o Colquiruna) parece haberlos señalado en un plano de alguno de los pueblos (quizá el de Carania), donde cada mojón aparecía identificado con una letra, un plano no muy diferente de los que conocemos para Yauyos y otras regiones en la misma época. ${ }^{27} \mathrm{El}$ intérprete también explicó que «quipocamallo quiere desir escriuano» y manifestó, quizás glosando un término propio de la administración imperial incaica, que Cristóbal Guaman, padre del testigo Alonso Atoc Naupa, fue «cacique que tubo poder del inga para mandar y gouernar a todos los casiques de aquel Repartimiento».

Fernández Colquiruna transmitió un relato fascinante, contenido en unos pocos folios, acerca de los acuerdos a los que llegaron los distintos caciques y comunes de la región de Yauyos — y la manera muy peculiar

${ }^{26}$ Expediente de la causa seguida por Melchor de Carbajal. 1688. BNP. Ms. B 899, f.104v.

${ }^{27}$ Prado Tello y Prado 1991: 167-168; Taylor 2000a. Estos dos casos sugieren que se comisionó la confección de diferentes planos durante la primera composición general de tierras. 
de sellar dichos pactos - tras la conquista inca de la zona. Para hacer frente a la ofensiva, los líderes de la parcialidad de Guaquis se vieron obligados a ceder en perpetuidad sus pastos a la parcialidad de Carania, a cambio de cuatro familias de plateros que labraran el metal para los poderosos señores del Cuzco. Esta es la historia que, según Colquiruna, los testigos contaron en aquella ocasión. ${ }^{28}$

${ }^{28}$ La cercanía de minas de plata, sobre todo al pueblo de Laraos, explica la existencia de parcialidades en tiempos de los incas que, como la de Yasapa ayllu, se especializaban en la explotación de los yacimientos y el trabajo del metal, en parte con fines tributarios como los que describe el documento de 1693 (Spalding 1984: 86). 


\section{Apéndice}

[f.103]

Suplica se lea.

Muy Poderoso Señor.

Don Melchor de Carbajal procurador general de los naturales deste reino en nombre de los prinsipales y común del repartimiento del pueblo de Santiago de Carania en los autos con los del pueblo de Piños sobre la posesión y propiedad de unas tierras y pastos y lo demás deducido. Digo que en estos autos y ciertas declaraciones hechas por algunos yndios antiguos en lengua general, las quales influyen mucho en la pretención de mis partes, y los abogados no las entienden ni se podrá hacer relación de ellas, y respecto de que vuestra Alteza tiene nombrado intérprete general, se ha de servir Vuestra Alteza de mandar que con citación de las partes si fuere necesario se redusga a castellano el dicho intérprete las dichas declaraçiones y fecho se me [entre renglones: dé] traslado por todo lo qual, a Vuestra Alteza pido y suplico assí lo provea $[f .103 v]$ y mande pido justicia y costas.

Don Melchor de Carvajal [rubricado].

El intérprete general redusga a lengua castellana las declaraciones que se refieren en este escrito ante el escrivano de cámara con citación de las partes. [Tres rúbricas].

Proveído lo de susso decretado y rubricado por los señores don Juan Gonzales de Santiago y don Francisco López del Castillo, presidente y oydores desta real audiencia, en audiencia pública que hicieron en veyntiquatro de abril de mil y seiscientos y noventa y tres ańos.

Francisco de Quessada [rubricado].

En cumplimiento de lo mandado por el decreto antezedente parezió ante mí el pressente escrivano de cámara el capitán Pablo Fernández Colquiruna yntérpetre [sic] general de los naturales de este reyno del qual [f.104] yo el pressente escrivano de cámara reseví juramento por Dios nuestro señor y una señal de cruz según forma de derecho so cargo del qual prometió desir verdad y traduçir en lengua castellana la declarassión que está en lengua general de los naturales que está presentada a foxas onse de los autos que se siguen por parte de don Thomás de Zepeda, casique principal y governador del repartimiento de Atunyauyos, provincia de Yauyos, y por el común de dicho repartimiento contra don Pedro Martín, casique principal y governador del repartimiento de Laraos y Aymaraes, en la provinsia de los Yauyos, y el común del pueblo de San Pedro de Piños; y siéndole mostrado las letras de dicha declarassión dijo lo siguiente:

Alonsso Atoc Naupa, yndio ansiano que ha bibido y se ha criado en puna, dixo como testigo que desde que nasió save y ha visto los mojones de las tierras y pastos del pueblo de Carania; así mismo a oydo desir a los indios más antiguos de aquel tiempo y en expecial a su abuelo como las tierras mojones y pastos eran del casique y común de sus indios del pueblo de Carania y por querer bien a su alma y por tener temor a Dios nuestro Seńor dirá la verdad lo que sabe y a bisto. 
Primeramente, dise que el mojón nombrado Ranra es del casique de Carania y que de allí se sigue Sanancancha [Sananca?], Caycayhorco Sococancha, Sanancacancha, Cochatopicancha es del pueblo de Carania que le dio quatro yndios plateros que hubo pacto y consierto sobre estas tierras entre dos casiques nombrados Cargua Ispilco $[y]$ Alonsso Atoc que el Ynga Yupangi y Topa Yupangi llegó al pueblo y tierra nombrado Guaquis que fue casique de dicho pueblo nombrado Cargua y el Inga lo mandó y pidió al casique de Guaquis quatro indios plateros y si no le dava luego le castigaría y por temor de este $[f .104 v]$ dicho el casique de Guaquiz por no tener en su pueblo indios plateros llegó a suplicar al casique del pueblo de Santiago de Carania que le hiciese merzed y diese la vida porque el Inga le havía dicho que le havía de castigar si no le dava luego indios plateros y que le agradesería y besaría sus manos y así vuestra merced me dé quatro indios plateros porque ay en su tierra para entregar al Ynga, yo lo daré a vuestra merced para siempre jamás unas tierras nombradas Ranra, Sananca Cancha, Caycayhorco, Sococancha, Cochatopicancha; el casique de Carania lo [sic] entregó quatro indios plateros. Y el casique de Guaquis nombrado Cargua juró en su antigua ley que las dichas tierras que le dava en trueque y cambio quatro yndios plateros no havía de pedir las dichas tierras ni hablar sobre ellas hasta el día del juiçio y diciendo esto lo cortó tanto y quanto el codo de su pie que era para cumplir y guardar el juramento de su antigua ley; y dixo más el dicho Cargua que el platero que le dava aunque ayan hecho muchos hijos y nietos que tuvieren no le ha de pedir el dicho Ispilco sino ha de ser suyo hasta para siempre jamás y el dicho casique Ispilco lo azeptó y resivió dichas tierras para la comunidad de sus yndios y suyo y también dicho Ispilco cortó el codo de su pie y se ajustaron el contrato ambos casiquez de Guaquis y Iauyos.

Asimesmo dise Alonsso Atoc que los mojones de Santiago de Carania save y ha visto: la primera [¿Atalirpo?] mojón; Guascacocha Cancha este nombre se ynterpreta y quiere desir Corral; Quinoa Cancha este nombre se ynterpreta tierras de árboles que llaman quingua; Canchanacancha mojón: este nombre se interpreta y quiere desir arroyuelo que corre el agua; hasta [a]quí llega los mojones del pueblo de Santiago de Carania [f.105] como está puesto en las letras.

I dise Alonsso Atoc que en todos estos tratos y contratos se hallaron presentes los casiques nombrados Chauca [¿?] que fue quipocamallo quiere desir escrivano; y Geuja Casique, y Cristóval Guaman Casique que tubo poder del Inga para mandar y governar a todos los Casiques de aquel repartimiento que fue medio cristiano por haver ya entrado los españoles a este reino este fue muy biejo y que siempre ha bibido en la puna. Este Cristóval Guaman fue padre del dicho Alonsso Atoc, todos los susodichos fueron testigos en el trato y contrato que tubieron ambos casiques de Guaquis y Yauios y el casique de Guamanmarca. Y esto según parese una firma más abajo que dise Alonsso Atoc.

Y haviéndosele mostrado otra declarassión que está a foxas dose de dichos autos que está asimesmo en lengua general. Dixo que traducida en lengua española es como se sigue. 
Prosigue

Declarassión Don Alonsso yndio ansiano casique que fue del pueblo de Yauyos que governava en tiempo de Guaynacapa Ynga siendo mosso. Dixo quel Inga Yupamgui tuvo por su hijo a Topa Yupangui Ynga estos governaban a este reyno y a todos los yndios mandava y repartieron a los yndios las tierras y chacras de puna carneros de la tierra y la llerva de coca; y que en el pueblo de Santiago de Carania havía muchos indios plateros. Y que en el pueblo de San Augustín de Guaquis no havía indios plateros y en dicho pueblo era casique nombrado Cargua Millui y que este dicho casique le embió recaudos dos beses disiendo si quería dar quatro yndios plateros a Espilco y dicho Espilco no quisso dar indios ningunos y para tres beses fue en persona Cargua Millui con todos sus prinçipales a rogar a Espilco a que le diesse quatro indios plateros para dar al Inga Yupangui y Topa Yupamgui porque el Inga le havía dicho que le havía de castigar si no le entregava luego indios plateros $[f .105 v]$ y por temor del dicho Ynga Cargua dixo a Espilco que le besaría sus manos y le diese la vida y dicho Espilco casique de Carania respondió que no podía dar palabra de dar indios plateros hasta consultar con sus principales y común de sus yndios. Haviendo entrado Espilco en consulta con todos sus principales e yndios si podia dar o no quatro yndios plateros en trueque de unas tierras salió la consulta que todos dixeron al casique Espilco que le diese; y en esta conformidad el casique de Guaquis, el casique de Santiago de Carania tubieron pacto y consierto en que dise el casique Cargua le daría las tierras de puna y otras tierras. El casique Espilco daría quatro indios plateros con que se ajustaron el dicho consierto el uno y el otro y resivió Cargua los quatro yndios plateros nombrado[s] Guaro Cara y la muger de este yndio se llamava Guarachumbi; otro indio viejo nombrado Noqui, la mujer de este yndio se llamava Colquicargua. Y el casique de Guaquis hizo juramento en su antigua ley que las tierras de puna y otras tierras que le dava en trueque y cambio no avía de pedir ni hablar hasta el día del juiçio. Así mismo hizo juramento Espilco y lo azeptó en todo; así mismo vido al señor marquez Don Francisco Pisarro y al capitán nombrado Soto y a Hernán Ponse que estos espańoles salieron de Cajamarca y llegaron al pueblo de Santiago de Carania y al pueblo de Guaquiz y el marquez don Francisco Pizarro mandaron a los indios de Carania y el de Guaquis resiviesen al encomendero en las tierras que tienen y poseen cada casique y así lo hizieron en aquel tiempo de Pizarro y nunca havían hablado el casique de Guaquis ni sus indios por las dichas tierras de puna y la dicha declarasión dijo estar escripta por el mes de julio ańo de mil quinientos y noventa y dos firmada de Don Alonsso. Y que lo que a dicho y declarado es la [f.106] verdad para el juramento que tiene fecho a su leal saver y entender y lo firmó.

Don Francisco de Quessada [rubricado].

Don Pablo Fernández Culquiruna [rubricado].

«Expediente de la causa seguida por Melchor de Carbajal». 1688. BNP. Ms. B 899

\section{(Transcripción de Laura Gutiérrez Arbulú)}




\section{BIBLIOGRAFÍA}

Abercrombie, Thomas. 2002. «La perpetuidad traducida: del "debate” al Taki Onqoy y una rebelión comunera peruana». En Jean-Jacques Decoster (ed.). Incas $e$ indios cristianos: elites indigenas e identidades cristianas en los Andes coloniales. Cuzco; Lima: Centro de Estudios Regionales Andinos Bartolomé de Las Casas; Asociacion Kuraka e Instituto Francés de Estudios Andinos, 79-120. https:// doi.org/10.4000/books.ifea.4080

Andrade Ciudad, Luis y Martha G. Bell. 2016. «Mapping Colonial Quechua through Trial Interpretations in Seventeenth-Century Cajamarca». Colonial Latin American Review. Volumen 25, número 4: 445-464. https://doi.org/10. $1080 / 10609164.2016 .1281006$

Argouse, Aude. 2014. «YY yo, ¿̨con quién voy a vivir?’ Carta de Doña Fabiana Lachos, 1661». Historia y Justicia. Volumen 3: 336-350.

Beyersdorff, Margot. 2007. "Covering the Earth: Mapping the Walkabout in Andean Pueblos de Indios». Latin American Research Review. Volumen 42, número 3: 129-160. https://doi.org/10.1353/lar.2007.0047

Cunill, Caroline. 2013. «Los intérpretes de Yucatán y la Corona española: negociación e iniciativas privadas en la fragua del imperio ibérico, siglo XVI». Colonial Latin American Historical Review. Volumen 1, número 4: 361-380.

Cunill, Caroline. 2018. «Un mosaico de lenguas: los intérpretes de la Audiencia de México en el siglo XVI». Historia Mexicana. Volumen 68, número 1: 7-48. https://doi.org/10.24201/hm.v68i1.3637

Cunill, Caroline. 2019. «Introducción: los intérpretes de las lenguas indígenas, ¿actores invisibles de la justicia en Amérca?». En Cunill, Caroline y Luis Miguel Glave (eds.). Las lenguas indígenas en los tribunales de América Latina: intérpretes, mediación y justicia (siglos XVI-XXI). Bogotá: Instituto Colombiano de Antropología e Historia, 9-14.

Cunill, Caroline y Luis Miguel Glave (eds.). 2019. Las lenguas indigenas en los tribunales de América Latina: intérpretes, mediación y justicia (siglos XVI-XXI). Bogotá: Instituto Colombiano de Antropología e Historia.

Dueñas, Alcira. 2015. «The Lima Indian Letrados: Remaking the República de Indios in the Bourbon Andes». The Americas. Volumen 72, número 1: 55-75. https://doi.org/10.1017/tam.2014.5

Durston, Alan. 2003. «La escritura del quechua por indígenas en el siglo XVII. Nuevas evidencias en el Archivo Arzobispal de Lima». Revista Andina. Volumen 37: 207-236.

Durston, Alan. 2007. Pastoral Quechua: The History of Christian Translation in Colonial Peru, 1550-1650. Notre Dame: University of Notre Dame Press.

Durston, Alan. 2008. «Native-Language Literacy in Colonial Peru: The Question of Mundane Quechua Writing Revisited». Hispanic American Historical Review. Volumen 88, número 1: 41-70. https://doi.org/10.1215/00182168-2007-078 
Durston, Alan. 2014a. «Cristóbal Choquecasa and the Making of the Huarochiri Manuscript». En Ramos, Gabriela y Yanna Yannakakis (eds.). Indigenous Intellectuals: Knowledge, Power, and Colonial Culture in Mexico and the Andes. Durham y Londres: Duke University Press, 151-169. https://doi. org/10.1215/9780822376743-008

Durston, Alan. 2014b. «Standard Colonial Quechua». En Salikoko S. Mufwene (ed.). Iberian Imperialism and Language Evolution in Latin America. Chicago: University of Chicago Press, 225-243.

Durston, Alan y George Urioste. 2013. «Las peticiones en quechua del curato de Chuschi (1678-1679)». En Curatola Petrocchi, Marco y José Carlos de la Puente Luna (eds.). El quipu colonial: estudios y materiales. Lima: Pontificia Universidad Católica del Perú, 379-440.

Estenssoro, Juan Carlos. 2015. «Las vías indígenas de la occidentalización. Lenguas generales y lenguas maternas en el ámbito colonial americano (1492-1650)». Mélanges de la Casa de Velázquez. Volumen 45, número 1: 15-36. https://doi. org $/ 10.4000 / \mathrm{mcv} .6097$

Fossa, Lydia. 2006. Narrativas problemáticas: los inkas bajo la pluma española. Lima: Pontificia Universidad Católica del Perú e Instituto de Estudios Peruanos.

Glave, Luis Miguel. 2011. «Memoria y memoriales: la formación de una liga indígena en Lima (1722-1732)». Diálogo Andino. Volumen 37: 5-23.

Glave, Luis Miguel. 2019. «Simiachi: el traductor o lengua en el distrito de la audiencia de Lima». En Cunill, Caroline y Luis Miguel Glave (eds.). Las lenguas indigenas en los tribunales de América Latina: intérpretes, mediación y justicia (siglos XVI-XXI). Bogotá: Instituto Colombiano de Antropología e Historia, 121-165.

Huamanchumo de la Cuba, Ofelia. 2015. "Los lenguas y los quipocamayocs: mediadores de comunicación en espacios propios de legalidad colonial». Signos Históricos. Volumen 17, número 33: 8-35.

Huamanchumo de la Cuba, Ofelia. 2016. «El oficio de lengua de un indio bilingüe de Chachapoyas Peru - Siglo XVI». Revista del Instituto Riva-Agüero. Volumen 1, número 1: 29-59.

Itier, César. 2011. «What Was the Lengua General of Colonial Peru?». En Heggarty, Paul y Adrian J. Pearce (eds.). History and Language in the Andes. Nueva York: Palgrave Macmillan, 63-85. https://doi.org/10.1057/9780230370579_4

Itier, César. 2015. "Quechua’ y el sistema inca de denominación de las lenguas». Mélanges de la Casa de Velázquez. Volumen 45, número 1: 37-56. https://doi. org $/ 10.4000 / \mathrm{mcv} .6113$

Jiménez de la Espada, Marcos (ed.). 1881-1897. Relaciones geográficas de Indias. Madrid: Tipografía de Manuel G. Hernández, 4 vols.

Jurado, Carolina. 2010. «Don Pedro de Dueñas, indio lengua. Un estudio de caso de la interpretación lingüística andino-colonial en el siglo XVII». Anuario de Estudios Bolivianos, Archivisticos y Bibliográficos. Volumen 15: 285-309. 
King, Kendall A. y Nancy H. Hornberger. 2006. «Quechua as a Lingua Franca». Annual Review of Applied Linguistics- Volumen 26: 177-194. https://doi. org/10.1017/S0267190506000092

Lentz, Mark. 2009. «Los intérpretes generales de Yucatán: hombres entre dos mundos». Estudios de Cultura Maya. Volumen 33: 135-158. https://doi. org/10.19130/iifl.ecm.2009.33.44

Lentz, Mark. 2019. "De "lenguas" de la Conquista a intérpretes del Juzgado de Indios». En Yannakakis Yanna y Martina Schrader-Kniffki (eds.). Los indios ante la justicia local. Intérpretes, funcionarios y litigantes en Nueva España y Guatemala (siglos XVI-XVII). Zamora: El Colegio de Michoacán, 21-38.

Mathis, Sophie. 2017. Una figura de la primera globalización de la América española: Vicente Mora Chimo o el itinerario original de un cacique ladino. De la costa norte del Perú a la Corte de España a principios del siglo XVIII. Lima: Universidad Nacional Agraria La Molina.

Matthew, Laura E. y Sergio F. Romero. 2012. «Nahuatl and Pipil in Colonial Guatemala: A Central American Counterpoint». Ethnohistory. Volumen 59, número 4: 765-783. https://doi.org/10.1215/00141801-1642743

Murra, John. 1998. «Litigation over the Rights of 'Natural Lords' in Early Colonial Courts in the Andes». En Hill Boone, Elizabeth y Thomas Cummins (eds.). Native Traditions in the Postconquest World. Washington, D.C.: Dumbarton Oaks, 55-62.

Novoa, Mauricio. 2016. The Protectors of Indians in the Royal Audience of Lima: History, Careers and Legal Culture, 1575-1775. Leiden; Boston: Brill/Nijhoff. https://doi.org/10.1163/9789004305175

Prado Tello, Elías y Alfredo Prado. 1991. Phelipe Guaman Poma de Ayala: Y no ay remedio. Lima: Centro de Investigaciones y Promoción Amazónica.

Puente Luna, José Carlos de la. 2014. «The Many Tongues of the King: Indigenous Language Interpreters and the Making of the Spanish Empire». Colonial Latin American Review. Volumen 23, número 2: 143-170. https://doi.org/10.1080/ 10609164.2014.917545

Puente Luna, José Carlos de la. 2016. "En lengua de indios y en lengua española: cabildos de naturales y escritura alfabética en el Perú colonial». En Izquierdo de la Cueva, Ana Luisa (ed.). Visiones del pasado. Reflexiones para escribir la historia de los pueblos indígenas de América. Ciudad de México: Universidad Nacional Autónoma de México, 51-113.

Puente Luna, José Carlos de la. 2018. Andean Cosmopolitans: Seeking Justice and Reward at the Spanish Royal Court. Austin: University of Texas Press.

Puente Luna, José Carlos de la y Víctor Solier Ochoa. 2006. «La huella del intérprete: Felipe Guaman Poma de Ayala y la primera composición general de tierras en el virreinato del Perú». Histórica. Volumen 30, número 2: 7-29. 
Radcliffe, Sara A. 1990. "Marking the Boundaries between the Community, the State and History in the Andes». Journal of Latin American Studies. Volumen 22, número 3: 575-594. https://doi.org/10.1017/S0022216X00020964

Rama, Angel. 1996. The Lettered City. Durham: Duke University Press.

Ramos, Gabriela. 2011. "Language and Society in Early Colonial Peru». En Heggarty, Paul Heggarty y Adrian J. Pearce (eds.). History and Language in the Andes. Nueva York: Palgrave Macmillan, 19-38.

Ramos, Gabriela. 2014. "Indigenous Intellectuals in Andean Colonial Cities». En Ramos, Gabriela Ramos y Yanna Yannakakis (eds.). Indigenous Intellectuals: Knowledge, Power, and Colonial Culture in Mexico and the Andes. Durham y Londres: Duke University Press, 21-38. https://doi. org/10.1215/9780822376743-002

Ramos, Gabriela y Yanna Yannakakis (eds.). 2014. Indigenous Intellectuals: Knowledge, Power, and Colonial Culture in Mexico and the Andes. Durham y Londres: Duke University Press. https://doi.org/10.1215/9780822376743

Rappaport, Joanne y Thomas Cummins. 2012. Beyond the Lettered City: Indigenous Literacies in the Andes. Durham: Duke University Press. https://doi. org/10.1215/9780822394754

Rostworowski, María. 1977. «La estratificación social y el hatun curaca en el mundo andino». Histórica. Volumen 1, número 2: 249-286.

Salomon, Frank y Mercedes Niño-Murcia. 2011. The Lettered Mountain: A Peruvian Village's Way with Writing. Durham: Duke University Press. https://doi. org/10.1215/9780822394341

Spalding, Karen. 1984. Huarochirí, An Andean Society under Inca and Spanish Rule. Stanford: Stanford University.

Tavárez, David. 2019. "Indigenous Intellectuals in Colonial Latin America" En Oxford Research Encyclopedia, Latin American History. https://doi.org/10.1093/ acrefore/9780199366439.013.531

Taylor, Gérald. 2000a. "Dos 'mapas' del pueblo de Cocha-Laraos (1595, 1597)». En Taylor, Gérald (ed.). Camac, camay y camasca y otros ensayos sobre Huarochiri y Yauyos. Lima: Instituto Francés de Estudios Andinos y Centro Bartolomé de Las Casas, 89-104.

Taylor, Gérald. 2000b. «Lengua general y lenguas particulares en la antigua provincia de Yauyos. Un documento quechua de Huarochirí-1608». En Taylor, Gérald (ed.). En Camac, camay y camasca y otros ensayos sobre Huarochiríy Yauyos. Cuzco: Instituto Francés de Estudios Andinos y Centro Bartolomé de Las Casas, 35-69. Yannakakis, Yanna. 2008. The Art of Being In-Between: Native Intermediaries, Indian Identity, and Local Rule in Colonial Oaxaca. Durham: Duke University Press. https://doi.org/10.1215/9780822388982

Yannakakis, Yanna. 2014. «Making Law Intelligible. Networks of Translation in Mid-Colonial Oaxaca». En Ramos, Gabriela y Yanna Yannakakis (eds.). 
Indigenous Intellectuals: Knowledge, Power, and Colonial Culture in Mexico and the Andes. Durham y Londres: Duke University Press, 79-103. https://doi. org/10.1215/9780822376743-005

Yannakakis, Yanna y Martina Schrader-Kniffki. 2016. «Between the 'Old Law' and the New: Christian Translation, Indian Jurisdiction, and Criminal Justice in Colonial Oaxaca». Hispanic American Historical Review. Volumen 96, número 3: 517-548. https://doi.org/10.1215/00182168-3601670

Yannakakis, Yanna y Martina Schrader-Kniffki. 2019. Los indios ante la justicia local. Intérpretes, funcionarios y litigantes en Nueva España y Guatemala (siglos $X V I-X V I I)$. Zamora: El Colegio de Michoacán.

Fecha de recepción: 15/II/2020

Fecha de aceptación: 24/VI/2020 